\title{
Scandinavian Journal of Food and Nutrition in transition
}

\section{Dear Reader,}

$\mathrm{T}$ his is the last issue of the Scandinavian Journal of Food and Nutrition, No 4/2007, concluding volume 51 . The journal started as "Näringsforskning" in Swedish (i.e. Nutrition Research) in 1957 with the aim of informing Swedish and Nordic readers about progress in nutritional sciences. It was directed to professionals working with nutrition such as dieticians, nutritionists, medical doctors and nurses, teachers of home economics, and not the least the Swedish food industry that was keen on applying new results for nutritional improvements of their products.

In 1961, the Swedish Nutrition Foundation was established and took over the journal as one way of realising its overall aim to promote nutrition research and its practical implications. The Swedish language was kept, occasionally with articles in the Danish and Norwegian languages and the aim was to satisfy the broad spectrum of readers with different kinds of articles, reviews, summaries and debate in the broad area of nutrition.

From 1992 the name of the journal was changed to Scandinavian Journal of Nutrition/Näringsforskning with the ambition to increase the number of subscribers and readers both within and outside the Nordic countries. Members of the Swedish Society of Nutrition were an important part of the readers who got a discounted subscription included in their membership fee. Similar but discounted subscriptions were offered to societies in the other Nordic countries, and at times the journal had Scandinavian News from Denmark, Finland, Iceland and Norway in each issue. The journal was made more consistently bilingual, i.e. English and Scandinavian languages. Original articles in English were welcomed and appeared more and more. The journal was produced in the offices of the Swedish Nutrition Foundation.

From 2002 a contract was signed with a wellreputed publisher of scientific journals, Taylor\& Francis, now Informa Healthcare/Taylor\&Francis, with the title "Scandinavian Journal of Nutrition", and the journal was published consistently in the
English language. The aim was to increase the attractiveness of publishing original articles as well as reviews in the journal and to increase the number of international subscribers through efficient marketing activities. However, neither of these expectations was realised, also not after broadening of the scope and change of name to Scandinavian Journal of Food and Nutrition from 2006.

The journal has been indexed in several databases, CAB Abstracts; Elsevier Bibliographic Databases; EMBASE (Excerpta Medica); Food Science and Technology Abstracts (FSTA); and SWEMED. However, applications to be indexed in Index Medicus/PubMed have failed so far. This fact and the absence of an official impact factor, are major and increasingly important obstacles in attracting good original articles, particularly from the biomedical area. With this background it was decided to discontinue the Scandinavian Journal of Food and Nutrition in its present form, volume 51 being the closing volume.

From 2008, the Scandinavian Journal of Food and Nutrition will be continued in two separate forms: One purely scientific open access journal named Food \& Nutrition Research (see adjacent advert), and a new information journal in Swedish, with certain articles in other Scandinavian languages, named Nordisk Nutrition (Nordic Nutrition).

\section{This issue}

This last issue contains four articles representing various aspects of nutrition in general and foodrelated nutrition. The study of Rothenberg et al. brings up novel aspects of preparing consistency modified nutritious foods for the benefit of elderly people and patients with impaired ability to chew and swallow ordinary foods. Such measures are important in supporting a good nutritional status in these subjects. The paper by Asgård et al. regards a study on diabetes type 2 patients, showing that fruit and vegetable intake was inversely related to oxidative stress. Plasma carotenoid levels showed negative correlations with inflammation, and were strongly positively associated with fruit and 
vegetable intake. In the study of Chiplonkar and Agte interesting associations between mild health complaints and micronutrient intake and status in Indian vegetarians are reported, with the conclusion that there is a need to increase micronutrient intakes of vegetarian populations especially regarding vitamin $\mathrm{C}$ and zink. Finally, the study of Okarainen et al. addresses the carcinogenic or cancer inhibitory potential of coffee extracts by using a genetically modified mouse strain $\left(A p c^{M i n /+}\right)$ with a high frequency of multiple intestinal neoplasia. Filtered and unfiltered coffee, differing in kahweol/cafestol content were compared, but neither one of these extracts influenced the tumour occurrence in this animal model.

\section{Many thanks}

At this point it would be appropriate to thank recent years editors, co-editors and editorial assistants for their devoted work throughout the years:

Bo Hallgren (Editor-in-chief 1979-95)

Gösta Samuelson (Editor-in-chief 1996-2005)
Anita Laser Reuterswärd (Assistant editor and editor 1990-2001)

Jan I Pedersen, Assim Dutaroy, Michael Fogelholm and Inge Tetens (Assistant editors/editors 2002-2007)

Susanne Bryngelsson (Assistant editor 2006-2007)

Agneta Hartlén (Editorial assistant 1996-2007)

The staff of Informa Healthcare/Taylor\&Francis

Nils-Georg Asp

Editor-in-chief

Welcome readers to the new journals

Next year we are pleased to welcome previous and new readers to the two new journals that will replace the Scandinavian Journal of Food and Nutrition.

Food \& Nutrition Research Nils-Georg Asp

Editor-in-chief

Nordisk Nutrition Susanne Bryngelsson

Editor-in-chief 